\title{
APLIKASI METRIK SIGMA DALAM PEMANTAPAN MUTU INTERNAL PADA PEMERIKSAAN UREUM DISALAH SATU LABORATORIUM RUMAH SAKIT KABUPATEN PANGANDARAN
}

\author{
Rizal Apriansyah Pratama ${ }^{1}$, Dewi Kania Yulianti ${ }^{2}$, Doni Setiawan ${ }^{1 *}$ \\ ${ }^{1}$ Program Studi D3 Analis Kesehatan, STIKes Muhammadiyah Ciamis, Jawa Barat, Indonesia \\ 'Laboratorium Patologi Klinik, RSUD Soekardjo Tasikamalaya, Jawa Barat, Indonesia \\ e-Mail : donisetiawan@stikesmucis.com
}

\begin{abstract}
Intralaboratory Quality Control in clinical laboratories is significant and helps detect errors early to improve quality and guarantee examination results. The guaranteed method can be done by applying the sigma metric, which can detect 690,000 errors per million opportunities or 30.9 probability without defects with a minimum sigma value category of 3 and a maximum sigma value of 6 . Urea is one of the clinical chemistry examination parameters that often has a sigma value $<3$. This study aims to determine the application of the sigma metric in internal quality assurance on urea examination in one of the Pangandaran district hospital laboratories. This research method is a descriptive-analytic based on the sigma value in internal quality assurance on urea examination in Pangandaran district hospital laboratories. Based on the study results, the value of sigma $3-<4$ or marginal in March and May 2021 at the average control level while at the pathological control level increased from 2 sigma in March to 3 sigma in May 2021 said to be marginal.
\end{abstract}

Keywords : chemistry clinic, kidney function, six sigma

\begin{abstract}
Abstrak
Pemantapan Mutu Internal di Laboratorium klinik merupakan sesuatu yang sangat penting secara rutin serta berguna dalam mendeteksi kesalahan dini sehingga dapat meningkatkan kualitas dan menjamin hasil pemeriksaan. Metode penjaminan tersebut dapat dilakukan dengan penerapan metrik sigma yang dapat mendeteksi 690.000 kesalahan per juta peluang atau 30,9 probabilitas tanpa cacat dengan kategori nilai sigma minimal 3 dan nilai sigma maksimal 6 . Salah satu parameter pemeriksaan kimia klinik yang kerap memiliki nilai sigma $<3$ adalah ureum. Penelitian ini bertujuan untuk mengetahui aplikasi metrik sigma dalam pemantapan mutu internal pada pemeriksaan ureum disalah satu laboratorium rumah sakit Kabupaten Pangandaran. Metode penelitian ini merupakan analitik deskriptif berdasarkan nilai sigma dalam pemantapan mutu internal pada pemeriksaan ureum disalah satu Laboratorium Rumah Sakit Kabupaten Pangandaran. Berdasarkan hasil penelitian didapat nilai sigma $\geq 3-<$ 4 atau marginal di bulan Maret dan Mei 2021 pada level kontrol normal sedangkan pada level kontrol patologis mengalami kenaikan nilai dari 2 sigma dibulan Maret menjadi 3 sigma dibulan Mei 2021 atau dikatakan marginal.
\end{abstract}

Kata Kunci : faal ginjal, kimia klinik, six sigma 
Pelayanan laboratorium klinik perlu menerapkan program pemantapan mutu internal yang cukup baik agar dapat memastikan hasil yang dapat diandalkan (Galindo-Méndez and López 2018). Pengaruh pemeriksaan laboratorium sangatlah besar dalam tindakan perawatan pasien, diagnosa, pemantauan obat, skrining dan pencegahan penyakit sehingga laboratorium perlu memberikan hasil pemeriksaan yang bermutu dengan cara memenuhi persyaratan praktik yang baik untuk memastikan keselamatan pasien (Frank et al. 2012).

Menurut Peraturan Menteri Kesehatan Republik Indonesia Nomor 43 Tahun 2013 menyatakan bahwa untuk pemeriksaan hematologi dan kimia klinik perlu dilakukan pemeriksaan bahan kontrol setelah periode pendahuluan pada setiap hari atau hari dimana pemeriksaan dilakukan sesuai dengan parameter yang diperiksa (Kemenkes 2013). Pemeriksaan laboratorium medis pada bidang kimia klinik meliputi beberapa parameter diantaranya alkalin fosfatase (ALP), gamma-glutamyl- transferase (GGT), amilase, kreatinin, asam urat, kolesterol total, trigliserida, total protein, albumin, bilirubin direk dan bilirubin indirek, alkalin aminotransferase (ALT), aspartate aminotransferase (AST) dan ureum (Abebe et al. 2018).

Metrik sigma merupakan salah satu metode yang digunakan dalam program peningkatan dan manajemen kualiatas berbasis proses yang dikembangkan oleh perusahaan Motorola pada tahun 1980-an dan pertama kali digunakan dalam bidang laboratorium klinik pada abad ke-21. Metode metrik sigma berperan dalam menilai kualitas kinerja dengan pembagian tingkatan sigma yaitu sigma minimum dengan nilai 3 dan sigma maksimum dengan nilai 6 atau hasil 99,99966\% bebas cacat (Xia et al. 2018). Penerapan metrik sigma dalam pemantapan mutu internal dapat menggambarkan penyimpangan dalam setiap proses dan menunjukan seberapa sering terjadi kecacatan yang mungkin terjadi (Dewi and Widiyanto 2015).

Menurut hasil penelitian yang dilakukan B. Vinodh Kumar, Thuthi Mohan 
terkait internal quality control pada 16 parameter pemeriksaan kimia klinik di Rumah Sakit Perawatan Sekunder di Chennai pada waktu antara Juli 2015 dan Juni 2016 terdapat beberapa hasil yang bermasalah pada ketepatan pemeriksaan ureum, albumin dan magnesium serta masalah ketelitian pada pemeriksaan kolesterol total (Kumar and Mohan 2018). Parameter pemeriksaan tersebut memiliki nilai sigma $<3$. Berdasarkan hasil observasi pada salah satu laboratorium rumah sakit yang ada di Kabupaten Pangandaran bahwa nilai sigma pemeriksaan ureum masih dibawah batas nilai sigma minimum yang relavan dengan sumber literatur dari penelitian dibeberapa Negara didunia serta perameter ureum di rumah sakit tersebut mengalami kenaikan jumLah pemeriksaan dari bulan November hingga Desember 2020 yang sebanding dengan kebutuhan pemeriksaan ureum di ruangan hemodialisa dan metode metrik sigma belum digunakan dalam pemantapan mutu internal pada parameter ureum sehingga kualitas pemeriksaan parameter ureum dapat ditingkatkan untuk menunjang keberhasilan terapi di ruangan hemodialisa di rumah sakit tersebut. Tujuan penelitian ini yaitu untuk mengetahui hasil aplikasi metrik sigma dalam pemantapan mutu internal pada pemeriksaan ureum disalah satu laboratorium rumah sakit Kabupaten Pangandaran.

Penelitian sebelumnya terkait metrik sigma atau six sigma dilakukan untuk melihat gambaran nilai sigma pada suatu pemeriksaan di laboratorium medis sehingga penelitian aplikasi metrik sigma dalam pemantapan mutu internal pada pemeriksaan ureum di salah satu rumah sakit di kabupaten pangandaran dilakukan hingga tahap evaluasi terkait gambaran nilai sigma pada pemeriksaan. Tahap evaluasi pada penelitian ini berperan dalam peningkatan kualitas pemeriksaan yang berdasar pada metode metrik sigma yaitu nilai sigma pada uji periode kontrol bulan sebelumnya dan aturan westgard yang terdapat pada uji periode kontrol bulan Mei 2021.

Bahan yang digunakan dalam penelitian ini adalah bahan kontrol merek Trulab N (27547) dan Trulab $P$ (27548) dengan reagen sesuai merek alat. Populasi dan sampel dalam penelitian ini merupakan seluruh bahan kontrol 
yang digunakan pada alat automated chemistry analyzer Biosino ZS sebanyak 50 sampel terdiri dari 20 sampel pada periode pendahuluan dan 30 sampel pada periode kontrol dengan masing - masing menggunakan bahan kontrol level normal dan patologis. Data sekunder pengukuran bahan kontrol diukur oleh laboratorium rumah sakit sebagai periode kontrol bulan Maret dan data primer pengukuran bahan kontrol oleh peneliti selama 20 hari dengan dua level kontrol sebagai periode pendahuluan dan dilanjutkan pengukuran bahan kontrol selama 30 hari sebagai periode kontrol bulan Mei. Data yang diperoleh dari hasil pengukuran bahan kontrol bulan Maret pada periode kontrol yang dilakukan oleh rumah sakit dibandingkan dengan data hasil pengukuran bahan kontrol pada periode kontrol bulan Mei dianalisis berdasarkan Metode metrik sigma dengan rumus :

Sigma $=(\mathrm{TEa}-\mathrm{Bias}) / \mathrm{CV}$

Komponen rumus sigma diantaranya adalah Total Error Allowable, bias dan koefisian variasi. Total error allowable (TEa) merupakan batas total eror yang diperbolehkan yaitu sebesar 9\% menurut Clinical Laboratory Improvement Amandement (CLIA) (Harr et al. 2013). Presisi adalah suatu bentuk kemampuan parameter pemeriksaan untuk dapat memberikan hasil yang konsisten, presisi memiliki batas maksimum sebesar 8\% (Kemenkes 2013) dan dihitung dengan rumus koefisien variasi (CV) sebagai berikut :

$$
\mathrm{CV} \%=(\text { Standar Deviasi } / \text { mean }) \times 100
$$

Bias atau selisih antara hasil pemeriksaan bahan kontrol dengan nilai yang sebenarnya, nilai bias merupakan komponen yang berperan dalam menilai akurasi suatu pemeriksaan yang memiliki batas toleransi sebesar $5,5 \%$ (Sepulveda 2013). Bias (d\%) dihitung melalui rumus berikut:

$$
\mathrm{d} \%=\frac{\text { mean-nilai benar bahan kontrol }}{\text { nilai benar bahan kontrol }} \times 100
$$


Data nilai rata - rata dan standar deviasi hasil periode pendahuluan yang diteliti berperan dalam pembuatan grafik levely - Jennings pada periode kontrol. Grafik levely - Jennings digunakan dalam penentuan kriteria penolakan pemeriksaan dan peringatan kesalahan yang berfungsi untuk melihat kesalahan sistematik, kesalahan acak atau malfungsi metode pemeriksaan berdasarkan aturan westgard. Aturan westgard yang berpotensi dilanggar berdasarkan metode sigma untuk dua level kontrol diantaranya $1_{2} S / 2{ }_{2} S / R_{4} S / 4{ }_{1} S$ dan $8 x$ (Westgard, 2014). Metode penelitian yang digunakan adalah analitik deskriptif berdasarkan nilai sigma dan aturan westgard.

Berdasarkan hasil penelitian pengukuran bahan kontrol level normal pada periode pendahuluan bulan April 2021 dapat dilihat pada Tabel 1.

Tabel 1. Data uji periode pendahuluan bulan April 2021

\begin{tabular}{|l|c|c|c|c|c|c|}
\hline Karakteristik & TV & $\bar{X}$ & SD & CV\% & d\% & \%TE \\
\hline Level Normal & 35,75 & 35,28 & 0,78 & 2,20 & 1,31 & 5,71 \\
\hline Level Patologis & 161,5 & 155,89 & 3,76 & 2,41 & 3,47 & 8,30 \\
\hline
\end{tabular}

Batas toleransi meliputi koefisien variasi (CV\%), bias (d\%) dan total error allowable digunakan dalam pemantapan mutu internal sebagai batas maksimum kesalahan berdasarkan nilai ketelitian dan ketepatan suatu pemeriksaan serta total seluruh kesalahan pada penelitian ini yaitu CV maksimum 8\%, allowable bias 5,5\% dan TEa 9\% (Kemenkes 2013); (Harr et al. 2013);(Sepulveda 2013).

Pengukuran bahan kontrol yang diperoleh dari data sekunder pada bulan Maret 2021 diperoleh nilai sigma sebesar $\geq 3-<4$ untuk level kontrol normal dan nilai sigma sebesar $\geq 2-<3$ untuk level kontrol patologis. Pengukuran 
bahan kontrol yang didapatkan dari data primer pada bulan Mei 2021 diperoleh nilai sigma sebesar $\geq 3-<4$ untuk level kontrol normal dan patologis.

Tabel 2. Data uji periode kontrol bulan Maret dan Mei 2021

\begin{tabular}{lccccccc}
\hline Karakteristik & TV & X & SD & CV\% & d\% & \%TE & Sigma \\
\hline & \multicolumn{7}{c}{ Maret 2021} \\
Level Normal & 35,75 & 36,18 & 0,85 & 2,36 & 1,19 & 5,90 & 3,31 \\
Level Patologis & 161,5 & 152,63 & 2,25 & 1,48 & 5,50 & 8,45 & 2,37 \\
& & \multicolumn{7}{c}{ Mei 2021} & & & & \\
Level Normal & 35,75 & 35,00 & 0,72 & 2,06 & 1,94 & 6,08 & 3,42 \\
Level Patologis & 161,5 & 157,17 & 2,54 & 1,62 & 2,68 & 5,92 & 3,90 \\
\hline
\end{tabular}

Data hasil perhitungan nilai mean (X) dan standard deviasi (SD) dari pengukuran bahan kontrol level normal dan patologis pada periode pendahuluan diplotkan ke dalam grafik levely - Jennings untuk deteksi jenis kesalahan berdasarkan aturan westgard pada periode kontrol bulan Maret 2021. Aturan westgard yang dilanggar pada periode kontrol bulan Mei 2021 adalah $1_{2} \mathrm{~S}$ dan $4_{1} \mathrm{~S}$ pada dua level kontrol yang diukur secara bersamaan. 


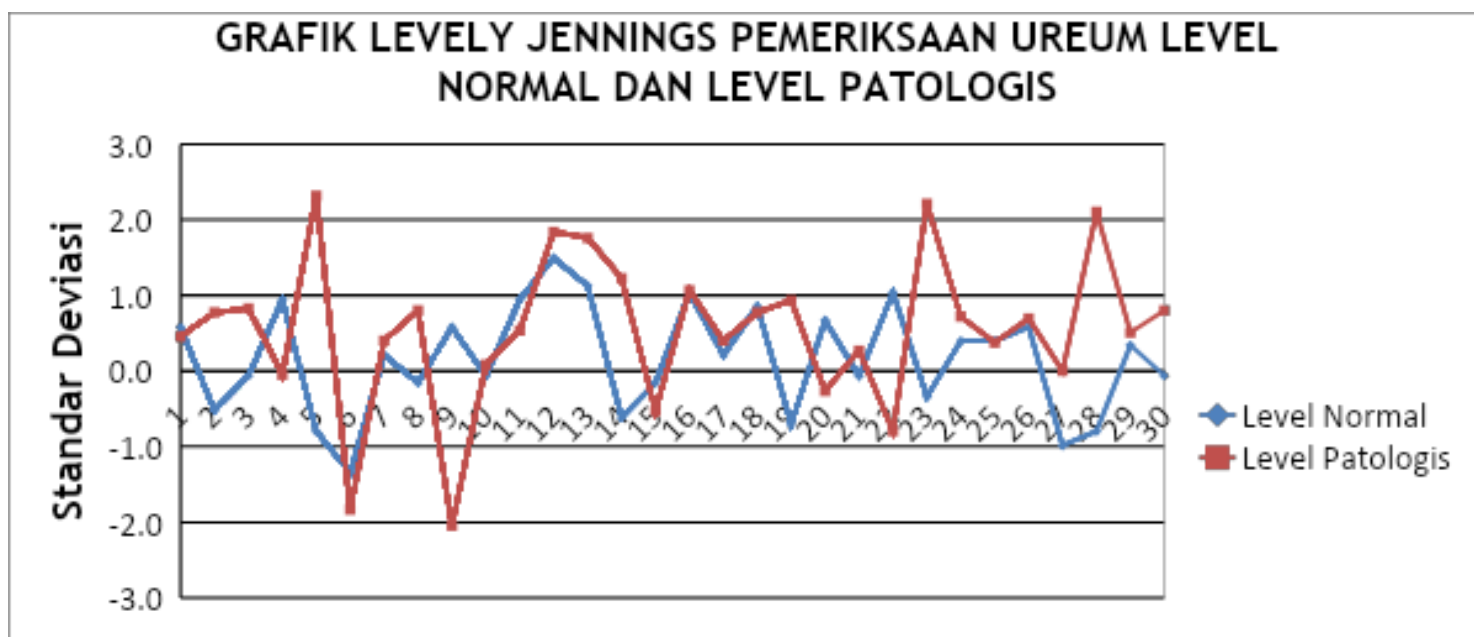

HARI / RUN

Gambar 1. Grafik levely - Jennings pemeriksaan ureum dengan level kontrol normal dan patologis

Nilai koefisien variasi (CV\%) menunjukan tingkat ketelitian suatu instrument atau metode dalam melakukan analisis. Data koefisien variasi pada (Tabel 1) dan (Tabel 2) tidak menunjukan adanya impresisi atau terganggunya tingkat akurasi jika dibandingkan dengan batas toleransi CV\% maksimum. Terdapat beberapa kesalahan yang sering terjadi yang berhubungan dengan tingkat ketelitian (presisi) yaitu kesalahan acak. Kesalahan acak merupakan kesalahan dengan pola yang tidak teratur diantaranya stabilitas instrumen yang kurang baik, variasi suhu, variasi reagen dan kalibrasi serta variasi teknik pada prosedur pemeriksaan (pipetasi, pencampuran dan waktu inkubasi) (Kemenkes 2013).

Data terkait nilai akurasi (d\%) atau bias menunjukan tingkat keakuratan suatu instrumen atau metode dalam melakukan pemeriksaan sampel. Data nilai bias pada (Tabel 1) dan (Tabel 2) memperlihatkan bahwa instrumen dan metode yang digunakan dalam melakukan proses analisis dapat dikatakan akurat tetapi cenderung berpotensi memiliki selisih hasil yang jauh dari nilai yang sebenarnya karena terdapat nilai pada bulan Maret 2021 yang sangat 
dekat dengan batas toleransinya. Kesalahan yang sering terjadi adalah kesalahan sistematik yang diakibatkan oleh standar kalibrasi/instrumentasi yang kurang baik serta berhubungan dengan tingkat ketepatan pemeriksaan yang ditandai dengan kesalahan yang berkepanjangan pada pola yang statis. Terdapat beberapa kesalahan sistematik dianntaranya : spesifisitas reagen rendah (kualitas rendah), kelemahan metode pemeriksaan, kurangnya tingkat ketepatan blanko sampel dan blanko reagen (kurva kalibrasi tidak linier), kualitas reagen kalibrasi yang kurang baik, performa alat (pipet) yang kurang akurat, ketidaksesuaian penggunaan panjang gelombang dan prosedur pelarutan reagen yang salah (Siregar et al., 2018).

Nilai \%TE merupakan nilai secara keseluruhan atau total yang memiliki batas tertentu untuk menetapkan suatu pemeriksaan dikatakan berjalan dengan baik atau tidak. Batas toleransi total error parameter pemeriksaan ureum menurut CLIA yaitu 9\%. Berdasarkan (Tabel 1) dan (Tabel 2) tidak menunjukan nilai \%TE yang melebihi batas nilai total error allowable. Nilai \%TE berperan dalam menghitung nilai sigma sehingga dapat menentukan keputusan yang diambil berdasarkan metode metrik sigma (Harr et al. 2013).

Pada Tabel 3 didapatkan hasil nilai sigma pada bulan Maret dan Mei 2021 yang menunjukan adanya peningkatan dari 2 sigma ke 3 sigma atau marginal untuk level patologis, sedangkan pada level normal masih dalam tingkatan nilai sigma 3 atau marginal. Nilai 3 sigma atau marginal setara dengan 93,3\% probabilitas tanpa cacat sebanding dengan 66,800 kesalahan dalam 1 juta peluang.

Grafik levely - Jennings yang telah digunakan pada Gambar 1 menandakan adanya beberapa kesalahan dan peringatan. Deteksi kesalahan dan peringatan tersebut dapat digunakan dalam memperkirakan suatu pemeriksaan dapat dilakukan atau tidak pada hari tertentu. Terdapat beberapa hari yang berpotensi mengalami kesalahan pemeriksaan terkait permasalahan sistematik dan malfungsi instrumen. 
Aplikasi Metrik Sigma Dalam Pemantapan Mutu Internal Pada Pemeriksaan Ureum di Laboratorium Rumah Sakit disalah satu Rumah Sakit di Kabupaten Pangandaran diperoleh hasil pemeriksaan bahan kontrol level normal pada bulan Maret dan Mei 2021 dengan nilai sigma dalam rentang $\geq 3$ < 4 atau dikatakan marginal dan pemeriksaan bahan kontrol patologis Mei 2021 mengalami peningkatan sejumLah 1 tingkatan sigma dari bulan Maret 2021 dengan nilai sigma awal sejumLah 2 sigma menjadi 3 sigma atau dapat dikatakan marginal. Pengaplikasian metrik sigma dalam kegiatan pemantapan mutu internal dapat membantu meningkatkan kualitas pemeriksaan berdasarkan nilai sigma yang didapat sehingga dapat dijadikan sebagai panduan untuk merancang kegiatan pemantapan mutu internal yang tepat.

Terima kasih kepada Program Studi D3 Analis Kesehatan STIKes Muhammadiyah Ciamis dan Pihak Rumah Sakit di Kabupaten Pangandaran atas kontribusinya dalam penelitian ini.

Tidaknya ada konflik kepentingan dalam penelitian ini, dengan tidak menulis nama rumah sakit.

Abebe, Molla, Mulugeta Melku, BamLaku Enawgaw, Wubet Birhan, Tekalign Deressa, Betelihem Terefe, and Habtamu Wondifraw Baynes. 2018. "Reference Intervals of Routine Clinical Chemistry Parameters among Apparently Healthy Young Adults in Amhara National Regional State, Ethiopia." PLOS ONE 13(8):1-13.

Dewi, Anindita Kusuma and Ibnu Widiyanto. 2015. "Sistem Informasi Kinerja Layanan Laboratorium Medis Dengan Metode Six Sigma.” Jurnal Sistem Informasi Bisnis 5(2):161-70.

Frank, Elizabeth, Tony Badrick, Herbert Stekel, Ken Sikaris, John Krahn, and Anne Vassault. 2012. “Quality of Management \& Quality of Analysis.” Pp. 
56-58 in International Federation of Clinical Chemistry and Laboratory Medicine.

Galindo-Méndez, Mario and y Alaciel Sánchez López. 2018. “Application of Clinical Goals and the Six Sigma Model in the Evaluation of Quality Control in Clinical Chemistry." Revista Del Laboratorio Clinico 11(1):20-27.

Harr, Kendal E., Bente Flatland, Mary Nabity, and Kathleen P. Freeman. 2013. "ASVCP Guidelines: Allowable Total Error Guidelines for Biochemistry." Veterinary Clinical Pathology 42(4):424-36.

James O. Westgard, Sten A. Westgard. 2014. “Introducing Westgard Sigma RulesTM." 10 Desember $2020 . \quad$ Retrieved (https://www.westgard.com/westgard-sigma-rules.htm).

Kemenkes. 2013. Peraturan Menteri Kesehatan Republik Indonesia Nomor : 43 Tahun 2013 Tentang Cara Penyelenggaraan Laboratorium Yang Baik. Jakarta: Menteri Kesehatan Republik Indonesia.

Kumar, B. Vinodh and Thuthi Mohan. 2018. "Sigma Metrics as a Tool for Evaluating the Performance of Internal Quality Control in a Clinical Chemistry Laboratory." Journal of Laboratory Physicians 10(02):194-99.

Sepulveda, Jorge. 2013. Accurate Results In The Clinical Laboratroy A Guide to Error Detection and Correction. First Edit. edited by A. Dasgupta. New York: Elsevier Inc.

Siregar, Maria Tuntun, Wieke Sri Wulan, Doni Setiawan, and Anik Nuryati. 2018. Bahan Ajar Teknologi Laboratorium Medik (TLM) Kendali Mutu. Vol. 7. 2018th ed. edited by B. A. Darmanto. Jakarta.

Xia, Jun, Su-feng Chen, Fei Xu, and Yong-lie Zhou. 2018. "Quality Specifications of Routine Clinical Chemistry Methods Based on Sigma Metrics in Performance Evaluation." Journal of Clinical Laboratory Analysis 32(3):1-5. 